\title{
Research on the new mode of intelligent maintenance and health management of coal mine equipment
}

\section{Xiangang Cao}

Xi'an University of Science and Technology

Mengyuan Zhang ( $\nabla$ zhangmengyuan0404@163.com )

Xi'an University of Science and Technology

\section{Yong Duan}

Xi'an University of Science and Technology

\section{Kexin Wu}

Xi'an University of Science and Technology

\section{Yanchuan Li}

Xi'an University of Science and Technology

\section{Research}

Keywords: coal mine equipment, big data, intelligent maintenance, health management

Posted Date: April 19th, 2021

DOI: https://doi.org/10.21203/rs.3.rs-408321/v1

License: (c) (i) This work is licensed under a Creative Commons Attribution 4.0 International License. Read Full License 


\section{Abstract}

Based on the analysis of the current challenges and deficiencies in the maintenance and management of coal mine equipment, an intelligent maintenance and health management system framework for coal mine equipment is designed for the big data characteristics of the life cycle of coal mine equipment. Taking the big data processing and analysis of coal mine equipment as the main line, it proposes and elaborates the key technologies of the intelligent maintenance and health management of coal mine equipment driven by big data, including the unified description and analysis of multi-source heterogeneous big data, and intelligent fault diagnosis of coal mine equipment. Technology, health evaluation and prediction technology, intelligent maintenance decision-making technology, etc. Through the implementation of the above-mentioned system architecture and key technologies, data-driven lifecycle intelligent decision-making is realized, which promotes the continuous optimization and improvement of equipment process management and reduces business costs. The proposed system architecture provides a reference model for subsequent development.

\section{Full Text}

Due to technical limitations, full-text HTML conversion of this manuscript could not be completed. However, the manuscript can be downloaded and accessed as a PDF.

\section{Figures}






Figure 1

Life cycle big data-driven system architecture 

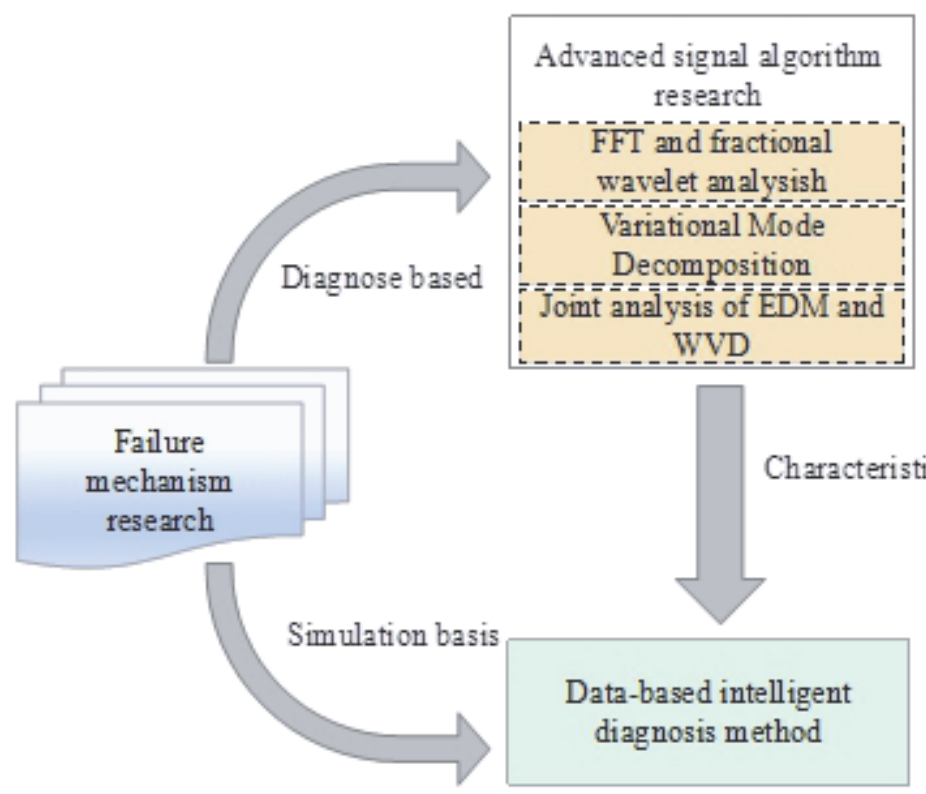

\section{Figure 2}

The logical relationship between the research directions of fault diagnosis

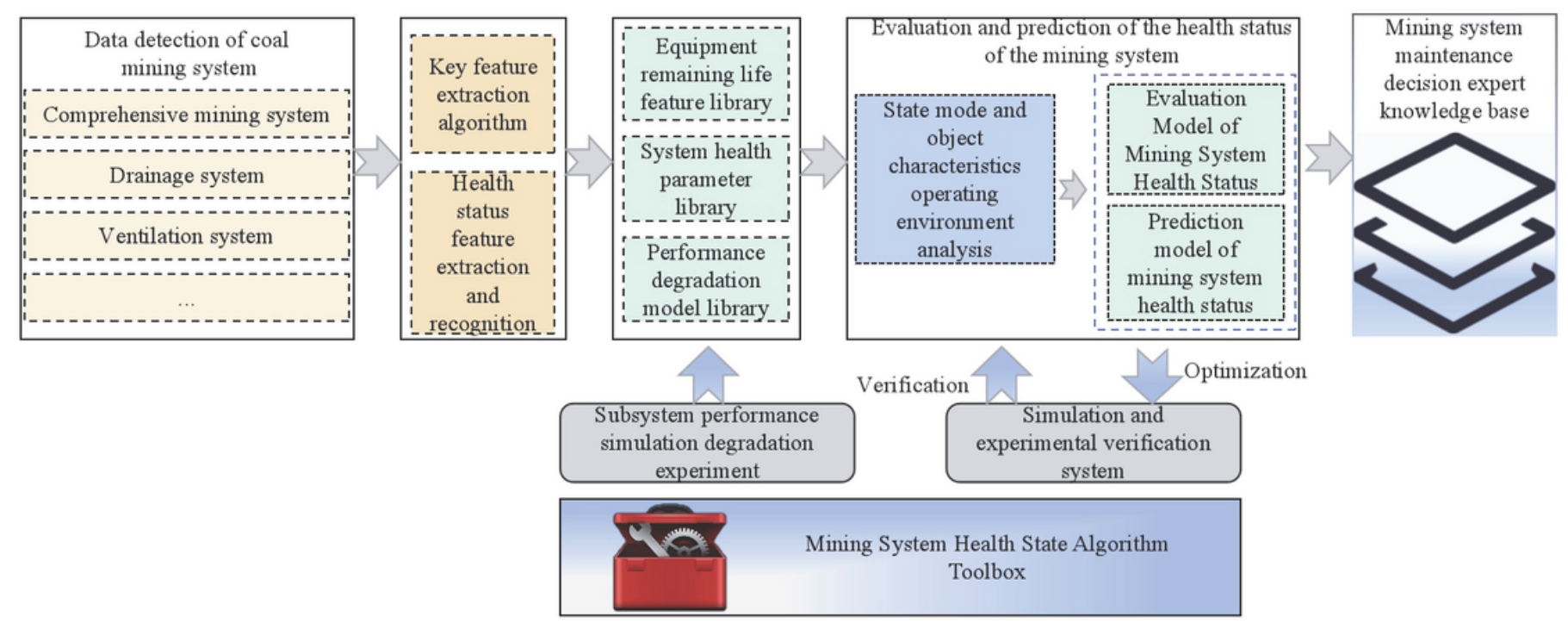

Figure 3

Mining system health evaluation, life prediction and maintenance decision-making mechanism 


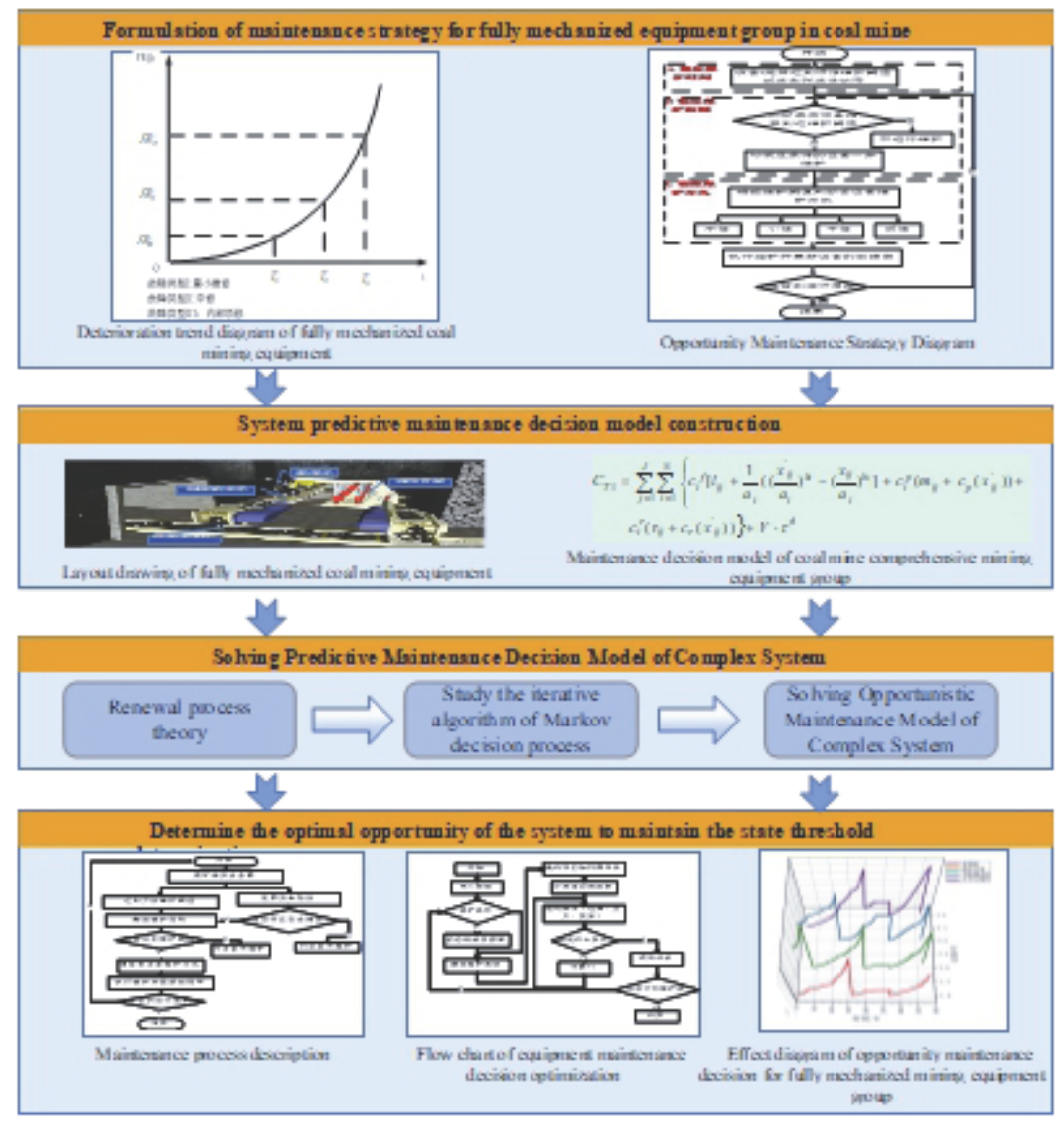

\section{Figure 4}

Two-layer opportunity maintenance predictive decision-making model of mining system integrating production scheduling and maintenance behavior 